\title{
Improved syntheses of halogenated benzene-1,2,3,4-tetracarboxylic diimides
}

\author{
Brian Zou, ${ }^{\dagger}$ Kellie A. Stellmach,${ }^{\dagger}$ Stella M. Luo, ${ }^{\dagger}$ Feven L. Gebresilassie, ${ }^{\dagger}$ Cathy K. Zhang, ${ }^{\dagger}$ Adam D. \\ Bass, ${ }^{\dagger}$ Daron E. Janzen, ${ }^{\dagger}$ Dennis D. $\mathrm{Cao}^{\dagger}$ \\ ${ }^{\dagger}$ Chemistry Department, Macalester College, 1600 Grand Avenue, Saint Paul, Minnesota 55105, United States \\ *Department of Chemistry and Biochemistry, Saint Catherine University, 2004 Randolph Avenue, Saint Paul, Minnesota \\ 55105 United States
}

Supporting Information Placeholder

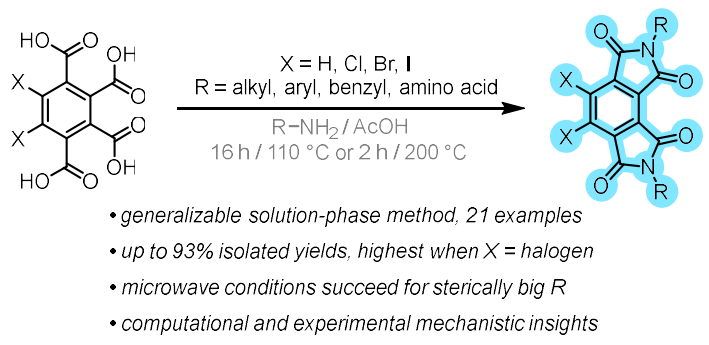

\begin{abstract}
The preparation of halogenated benzene-1,2,3,4-tetracarboxylic diimide derivatives is challenging because of the possibility of competitive incorrect cyclizations and $\mathrm{S}_{\mathrm{N}} \mathrm{Ar}$ reactivity. Here, we demonstrate that the direct reaction of benzene-1,2,3,4tetracarboxylic acids with primary amines in acetic acid solvent successfully provides a range of desirable ortho-diimide products in good yields. Furthermore, we demonstrate that sterically challenging N-derivatizations can be readily achieved under microwave reactor conditions, and that $S_{N} A r$ reactivity is only observed when excess amine is used. The halogenated diimides described here are attractive building blocks for organic materials chemistry.
\end{abstract}

Aromatic diimides, also known as bis(dicarboximide)s, are the linchpin of a diversity of organic materials encompassing vivid pigments and dyes, ${ }^{1-3}$ thermally robust polymers, ${ }^{4}$ and $n-$ type electronic materials. ${ }^{5,6}$ The electron-withdrawing nature of the cyclic imides lends itself to the creation of n-type semiconducting materials. ${ }^{3}$ The annulation of aromatic rings with cyclic imides tends to lead to more significant LUMO-lowering effects than HOMO-lowering effects, thus resulting in red-shifted bandgaps and absorption profiles. Aromatic diimides derived from benzene (PMDI), naphthalene (NDI), and pyrene (PDI) (Figure 1a) have received significant research attention because of their facile syntheses and amenability to derivatization at both the core and imide $\mathrm{N}$ positions. ${ }^{7-10}$ While changes in $\mathrm{N}$ functionalization are often exploited for tuning solid-state packing behavior and solubility profiles, ${ }^{11-13}$ core modification through substitution and metal-mediated cross-coupling reactions of halogenated aromatic diimides results in fine control over energy levels and electronic structure. ${ }^{7,10}$ In recent years, researchers have developed new strategies for incorporating cyclic imides onto a growing number of aromatic scaffolds, resulting in interesting redox activity ${ }^{14}$ and near-IR absorptions. ${ }^{15}$

We recently began exploring the ortho-diimide structural isomer of the well-known pyromellitic diimide, which is known as mellophanic diimide (MDI), ${ }^{16-19}$ and have discovered that it has significant potential as a building block in the construction of compounds with properties of interest to organic materials chemists (Figure 1b,c). Core dichlorinated N,N'-dihexyl MDI $\left(\mathbf{C l}_{2}\right.$-MDI-Hex), for example, readily undergoes both $\mathrm{S}_{\mathrm{N}} \mathrm{Ar}$ and Pd-catalyzed substitutions with aromatic ortho dinucleophiles to lead to a range of highly chromophoric and electron-accepting hetero- and azaacene structures. ${ }^{20,21}$ The development of MDI as a building block is further attractive because it is derived from 1,2,3,4-tetramethylbenzene, which is a byproduct of durene synthesis and a constituent of petroleum extract that has no significant industrial use. ${ }^{22}$ With these observations in mind, we set out to establish generalizable synthetic methods for obtaining differently halogenated MDI derivatives.

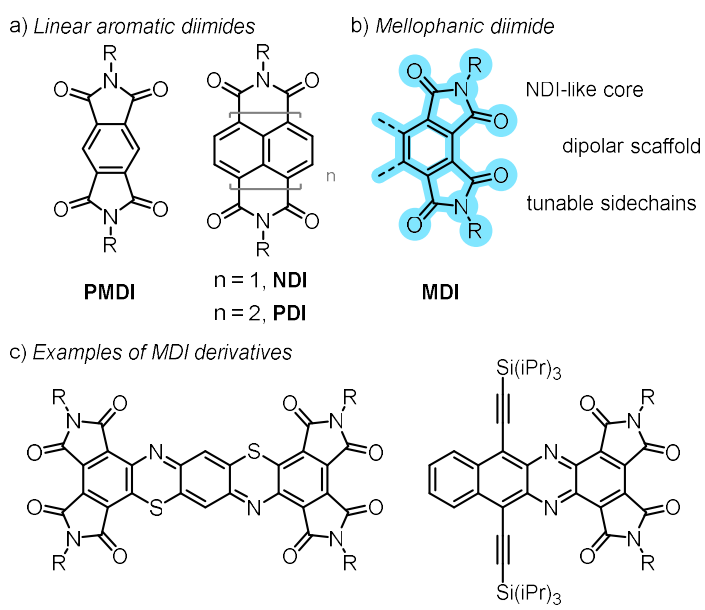

Figure 1. Structural formulas of a) pyromellitic diimide (PMDI), naphthalene diimide $(\mathrm{n}=1, \mathrm{NDI})$, and perylene diimide $(\mathrm{n}=2$, PDI), b) mellophanic diimide (MDI), and c) heteroacene MDI derivatives that are near-IR absorbing electron acceptors.

Results and Discussion. Conventionally, aromatic diimides are synthesized by condensation between the relevant aromatic cyclic dianhydride and an amine, a process which proceeds through an amide-carboxylic (amic) acid intermediate. Extending this approach to the synthesis of ortho aromatic diimides such as mellophanic diimide, however, is complicated by the possibility of incorrect cyclizations to yield 3,6- 
dicarboxyphthalimide byproducts. Two strategies were identified by Fang et. al for overcoming this challenge: 1) room-temperature amic acid formation followed by acetic anhydride-mediated dehydration and 2) high-temperature equilibration of the reaction mixture to reach the MDI thermodynamic product (Fig 2a). ${ }^{18}$ While both of these methods were successful for synthesizing N,N'-diaryl MDI compounds, we found that they could not be reliably extended toward either N,N'-dialkyl- or corechlorinated MDIs because of competing nucleophilic aromatic substitution reactions and significant 3,6-dicarboxyphthalimide formation. Inspired by the mellitic triimide synthesis developed by Rose et. al, ${ }^{23}$ we were previously able to obtain N,N'-dihexyl-4,5-dichloro-MDI ( $\mathbf{C l}_{\mathbf{2}}$-MDI-Hex) after the 3-day solidstate dehydration of an ammonium carboxylate salt (Fig. 2b). ${ }^{20}$ In further explorations, however, we found that this solid-state method could not be consistently extrapolated to differently halogenated benzene tetracarboxylic acids, and furthermore was not successful with more sterically demanding amines. As a result of further synthetic exploration, here we report our findings that the direct solution-phase reaction between benzene-1,2,3,4tetracarboxylic acids and primary amines is a widely generalizable method for synthesizing MDI derivatives of a variety of $\mathrm{N}$ substitutions and core halogenations (Fig. 3c).

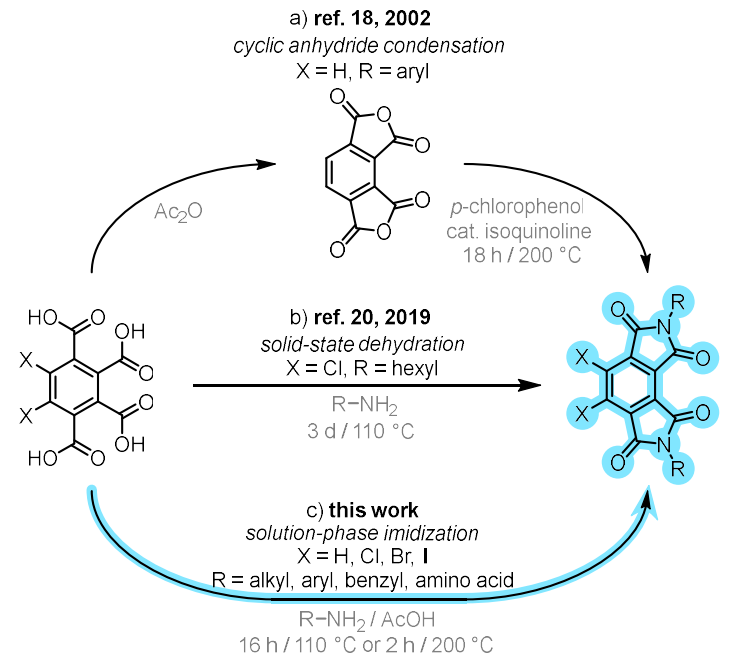

Figure 2. The historical development of synthetic methods for the preparation of MDI compounds began with a) conventional imidization of a dianhydride precursor, then b) solid-state dehydration of ammonium carboxylate salts to obtain dichlorinated MDIs, and presented here, c) the direct solution-phase condensation of tetracarboxylic acids with amines.

Synthesis. The commercially available 1,2,3,4-tetramethylbenzene was chlorinated, ${ }^{20}$ brominated, ${ }^{24}$ or iodinated ${ }^{25}$ following literature procedures to yield intermediates $\mathbf{1 - X}(\mathrm{X}=$ $\mathrm{Cl}, \mathrm{Br}$, or I) which were then subjected to exhaustive oxidation by 10 eq. of $\mathrm{KMnO}_{4}$ in $\mathrm{tBuOH} / \mathrm{H}_{2} \mathrm{O}(1 / 1: \mathrm{v} / \mathrm{v})$ to provide the halogenated benzene-1,2,3,4-tetracarboxylic acids. Although many $\mathrm{KMnO}_{4}$ methylarene oxidation procedures use pyridine as a co-solvent to improve reactant solubility, we have found that the use of $\mathrm{tBuOH}$ co-solvent reduces the equivalents of $\mathrm{KMnO}_{4}$ required to achieve full oxidation and furthermore is less prone to exotherm during the addition of $\mathrm{KMnO}_{4}$. Complete removal of reaction solvent prior to acidification of the carboxylate intermediate is important for avoiding the formation of t-butyl ester impurities. Our largest scale oxidation
(20.0 g, $98.5 \mathrm{mmol}$ of 1-CI) proceeded smoothly to provide the tetraacid $\mathbf{2 - C l}$ in $85 \%$ isolated yield.

Although we initially followed our previously developed solid-state dehydration protocol for synthesizing $\mathbf{3}-\mathbf{X}-\mathbf{R}$, we were motivated by inconsistent yields and long reaction times to investigate a solution-phase method. Unexpectedly, simply heating the tetraacids $\mathbf{2}-\mathbf{X}$ with primary amines in acetic acid solvent followed, if necessary, by the precipitation of products with the addition of water or $\mathrm{MeOH}$ to the reaction mixture, provided MDIs 3-X-R in up to $93 \%$ isolated yield. In some cases, a small amount of additional product can be recovered by extraction of the aqueous filtrate with $\mathrm{CH}_{2} \mathrm{Cl}_{2}$. Although the reaction byproducts are often polar and soluble enough in $\mathrm{AcOH}$ to be removed during the filtration process, additional purification can be easily achieved by passing the crude product mixture through a $\mathrm{SiO}_{2}$ column.
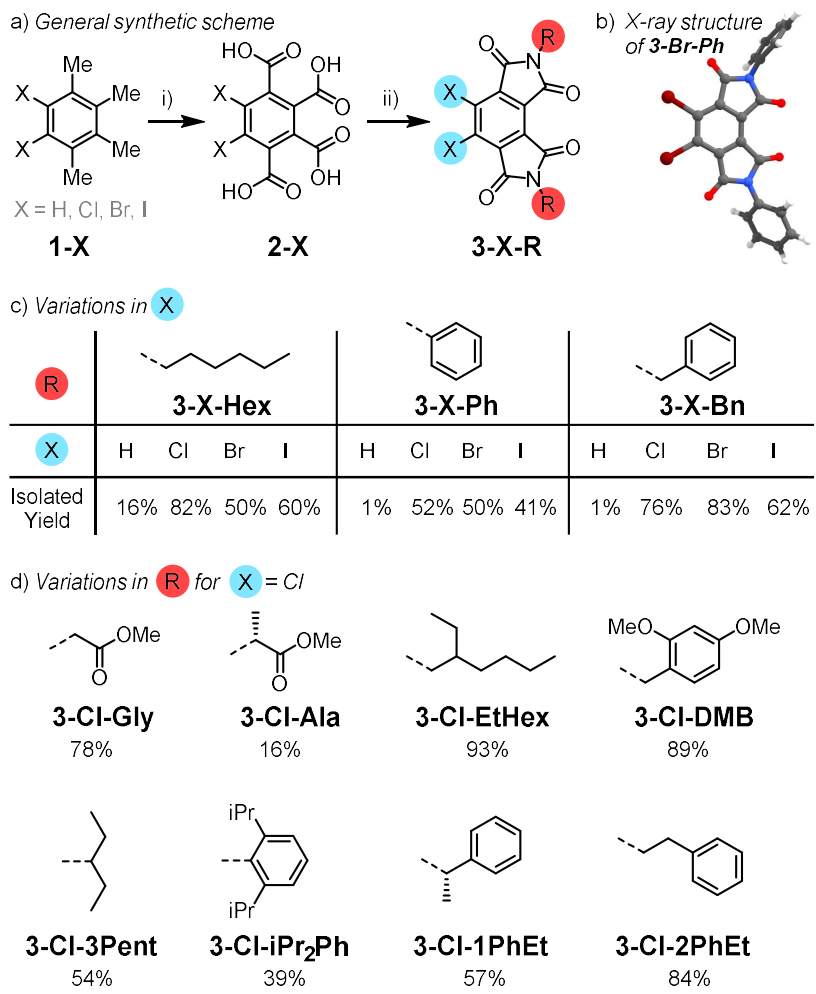

Figure 3. a) Synthetic pathway for the preparation of $\mathbf{3}-\mathbf{X}-\mathbf{R}$ compounds. i) 10 eq. $\mathrm{KMnO}_{4} / \mathrm{tBuOH} / \mathrm{H}_{2} \mathrm{O}$; ii) $\mathrm{RNH}_{2} / \mathrm{AcOH}$. b) Single crystal X-ray structure of 3-Br-Ph. c) Table of isolated yields for a variety of $\mathbf{3}-\mathbf{X}-\mathbf{R}$ compounds with a focus on variation in X. Reaction conditions: $0.1 \mathrm{M}$ 2-X in $\mathrm{AcOH}, 2.1$ equiv $\mathrm{R}-\mathrm{NH}_{2}$, $110^{\circ} \mathrm{C}, 16 \mathrm{hr}$.

This method is successful with a variety of amines and there is no discernible trend between the identity of the halogen and the reaction yield. Hexylamine, aniline, and benzylamine react smoothly with $\mathbf{2 - X}(\mathrm{X}=\mathrm{Cl}, \mathrm{Br}$, and $\mathrm{I})$ in good yields to produce a suite of 3-X-R compounds. Single crystal X-ray data for 3$\mathbf{B r}-\mathbf{P h}$ confirms the MDI constitution of the products (Figure $3 \mathrm{~b}$ ). It is notable, as will be discussed below, that yields tend to be higher for the halogenated 3-X-R compounds than the nonhalogenated ones. Amino acid methyl esters can also be readily converted into MDIs, which suggests they may be interesting building blocks for self-assembling small molecules. ${ }^{26,27}$ Attempts to perform imidization with 6-amino-1-hexanol, 
however, resulted in complex mixtures as a consequence of acetate ester formation with the free alcohol. With these results in hand, we attempted to install more sterically demanding $\mathrm{N}$ groups such as branched alkyl chains and 2,6-dialkylaryl groups since these are commonly used by organic materials chemists to manipulate crystal packing and solubility. Although 2ethylhexylamine reacted readily with $\mathbf{2 - H}$ to yield 3-H-EtHex, imidization of $\mathbf{2}-\mathbf{H}$ with the more sterically hindered nucleophiles such as $(S)$-1-phenylethan-1-amine and 2,6-diisopropylaniline proved to be more recalcitrant. We were unable to isolate any products after applying our standard reaction method, and heating $(S)$-1-phenylethan-1-amine with $\mathbf{2}-\mathbf{H}$ for 3 days at $110{ }^{\circ} \mathrm{C}$ resulted in only $11 \%$ formation of $\mathbf{3 - H}-\mathbf{1 P h E t}$. These low yields for sterically hindered amines were also found when attempting these same reactions using our older solid-state approach (Figure 4).

To overcome this slow reaction rate, we turned to microwave reaction conditions. Gratifyingly, reacting 2-Cl and $(S)$-1-phenylethan-1-amine at $200{ }^{\circ} \mathrm{C}$ for 24 hours led to $58 \%$ isolated yield for 3-H-1PhEt. Under these forcing conditions, an important consideration is whether nucleophilic aromatic substitution $\left(\mathrm{S}_{\mathrm{N}} \mathrm{Ar}\right)$ reactions at the aryl halides start to take place when $\mathrm{X}=$ halogen. In our trials, we did not observe significant levels of $S_{N} A r$ reactivity when 2.1 equiv of amine was reacted with tetraacid 2-Cl. However, when 12 equivalents of $(S)$-1-phenylethan-1-amine were reacted with $\mathbf{2 - C l}$, we did observe core-diaminosubstituted derivatives in the resulting product mixture.

\begin{tabular}{|c|c|c|c|c|c|}
\hline & $\mathrm{x}$ & $\mathrm{H}$ & $\mathrm{C}$ & $\mathrm{Cl}$ & $\mathrm{Cl}$ \\
\hline Solid-state Heating & $110^{\circ} \mathrm{C} / 3 \mathrm{~d}$ & - & $1 \%$ & $9 \%$ & $4 \%$ \\
\hline $\begin{array}{l}\text { Conventiona Heating } \\
(0.1 \mathrm{M} \text { in } \mathrm{AcOH})\end{array}$ & $110^{\circ} \mathrm{C} / 16 \mathrm{hr}$ & $0 \%$ & $57 \%$ & $39 \%$ & $54 \%$ \\
\hline \multirow[t]{4}{*}{$\begin{array}{l}\text { Microwave Heating } \\
(0.1 \mathrm{M} \text { in } \mathrm{AcOH})\end{array}$} & $200^{\circ} \mathrm{C} / 2 \mathrm{hr}$ & $11 \%$ & $42 \%$ & $66 \%$ & $70 \%$ \\
\hline & $200^{\circ} \mathrm{C} / 24 \mathrm{hr}$ & $58 \%$ & - & - & - \\
\hline & $\begin{array}{l}200^{\circ} \mathrm{C} / 2 \mathrm{hr} \\
\text { excess amine }\end{array}$ & $46 \%$ & - & - & - \\
\hline & $\begin{array}{l}200^{\circ} \mathrm{C} / 24 \mathrm{hr} \\
\text { excess amine }\end{array}$ & $48 \%$ & - & - & - \\
\hline
\end{tabular}

Figure 4. Comparison of isolated yields for imidizations between $\mathbf{2 - X}$ and sterically demanding amines under varying reaction conditions.

Mechanistic Insights. Our first attempted synthesis of 3-H1PhEt under microwave conditions was performed at $200{ }^{\circ} \mathrm{C}$ for $2 \mathrm{hr}$ of reaction time and resulted in $11 \%$ isolated yield. Both running the reactions for longer $\left(200{ }^{\circ} \mathrm{C}\right.$ for 24 hours $)$ or with more equivalents of nucleophile (12 equiv. amine, $200{ }^{\circ} \mathrm{C}$ for 2 or 24 hours) improved the isolated yield, to $58 \%$ and $46 \%$, respectively. It is worth noting that the excess amine approach is not feasible under microwave conditions when $\mathrm{X}=$ halogen because of the competitive $\mathrm{S}_{\mathrm{N}} \mathrm{Ar}$ reactions. From a mechanistic perspective, these observations suggest that in $\mathrm{AcOH}$ solvent, the reaction is likely taking place under overall equilibrating conditions. To gain more insight into the reaction process, we performed a ${ }^{1} \mathrm{H}$ NMR time-course study of the reaction between 2-H and $(S)$-1-phenylethan-1-amine in $\mathrm{d}_{4}$-acetic acid at $110^{\circ} \mathrm{C}$. Upon dissolving only $\mathbf{2 - H}$, the ${ }^{1} \mathrm{H}$ NMR spectrum reflects the presence of a complex mixture of anhydrides corresponding to intermediates with or without symmetry around the central benzene ring. Although we cannot rule out cyclic anhydride formation, we believe that mixed acetic anhydride formation is more likely based on the solubility of the reaction intermediates. Upon addition of the amine and heating for 5 minutes, a number of different intermediates are detected by ${ }^{1} \mathrm{H}$ NMR spectroscopy and formation of the desired MDI product is first observable after 20 minutes of reaction time. After 19 hours, the mixture resolves itself into being primarily four species, three with symmetry around the benzene core and one without. After 11 days of reaction time, the desired product constitutes only $18 \%$ of the product mixture, which highlights the value of microwave reaction conditions for achieving higher yields on a reasonable time scale. The NMR spectrum of the reaction after a total of 31.5 days at $110^{\circ} \mathrm{C}$ shows that the product distribution reaches a roughly 1:1:1 ratio of 3-H-1PhEt, 4-H-1PhEt, and 5H-1PhEt (Figure 5c).

We were able to tentatively assign the structure of the reaction intermediates by performing column chromatography on incomplete reaction mixtures and analyzing the filtrates collected during reaction workups. Of these, the most notable intermediates are dicarboxyphthalimides $\mathbf{4 - X}-\mathbf{R}$ and $\mathbf{5 - X}-\mathbf{R}$, which correspond to the asymmetric and symmetric possibilities, respectively, for monophthalimide formation between the tetraacids $\mathbf{2 - X}$ and an amine. It is again worth noting that during the reaction, however, it is difficult to rule out whether mixed acetic acid anhydride derivatives are the dominant species. Liquid chromatography mass spectrometry analysis of crude reaction mixtures corroborates the ${ }^{1} \mathrm{H}$ NMR and preparatory observations of 4-X-R and $\mathbf{5 - X}-\mathbf{R}$ as the primary reaction byproducts, but also reveal one other identifiable product corresponding to a diamidophthalimide species $\mathbf{6 - X - R}$. We believe this isomer is more likely because the analogous diamido derivative of $\mathbf{4 - X}$ $\mathbf{R}$ should be more likely to proceed to cyclize into $\mathbf{3}-\mathbf{X}-\mathbf{R}$. 


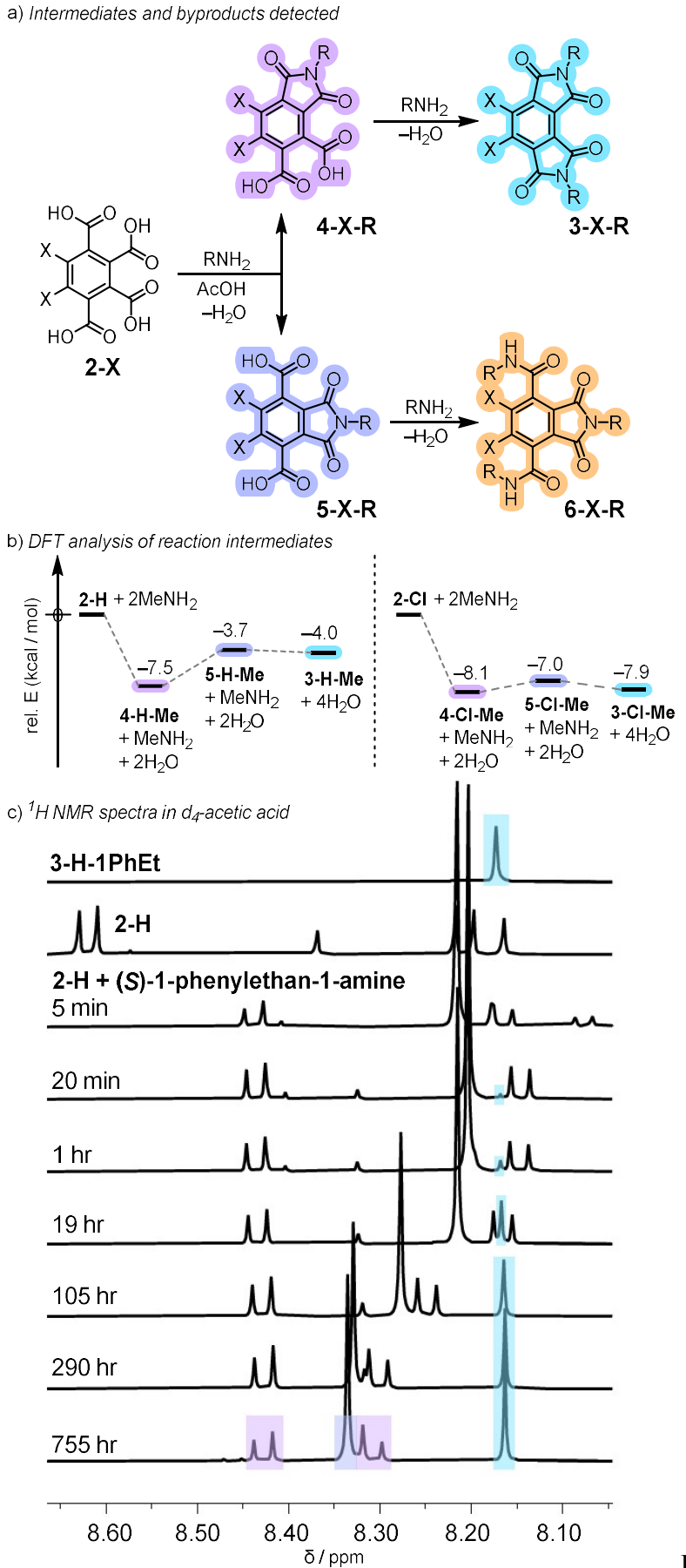

ure 5. a) A simplified schematic of reaction intermediates and byproducts during the formation of 3-X-R. b) A comparison of DFTcalculated energies for $\mathrm{X}=\mathrm{H}$ or $\mathrm{Cl}$ and $\mathrm{R}=\mathrm{Me}$ in implicit $\mathrm{AcOH}$ solvent (M062X / 6-31G(d)). c) ${ }^{1} \mathrm{H}$ NMR time-course study of the reaction between $2-\mathrm{H}$ and $(S)$-1-phenylethan-1-amine in $\mathrm{d}_{4}$-acetic acid at $110^{\circ} \mathrm{C}$, focused on the aromatic region.

From a purely statistical perspective, intermediates $\mathbf{4 - X}-\mathbf{R}$ and $\mathbf{5 - X}-\mathbf{R}$ should be formed in a 3 to 1 ratio because both the 1 - and 2-carboxamide derivatives of $\mathbf{2 - X}$ can dehydrate into intermediate $\mathbf{4 - X - R}$, while only the 2-carboxamide can cyclize into intermediate 5-X-R. To add context to our understanding, we performed density functional theory calculations (M062X/6-31G(d)) with implicit acetic acid solvent to evaluate the energy landscape of the reaction for the reaction between methylamine and either $\mathbf{2 - H}$ or $\mathbf{2 - C l}$. In both cases, the formation of the less symmetric 4-X-Me is thermodynamically favorable compared to the formation of 5-X-Me. Interestingly, the transformation of 4-H-Me into 3-H-Me is found to be an uphill process by $3.5 \mathrm{kcal} / \mathrm{mol}$, while the analogous conversion of 4-Cl-Me into 3-Cl-Me costs only $0.3 \mathrm{kcal} / \mathrm{mol}$. Although these calculations do not account for the added complexities of mixed anhydride formation or R group identity, they do correlate with our experimental findings that $\mathbf{3}-\mathbf{X}-\mathbf{R}$ formation is higher yielding when $\mathrm{X}=$ halogen. Taken together, it is reasonable to posit that the statistical advantage of monophthalimide formation balances against substrate-specific energetic differences to influence overall conversion into MDI products.

In conclusion, we have developed methods for the preparation of a wide range of 5,6-dihalobenzene-1,2,3,4-bis(dicarboximides) from the direct solution-phase condensation of benzene-1,2,3,4-tetracarboxylic acids and primary amines in acetic acid solvent. The preparation of compounds with sterically demanding groups at the $\mathrm{N}$ atoms of the imides can be achieved readily under microwave conditions. Experimental and computational studies suggest that the reaction can take place under equilibrium conditions that are favored both statistically and thermodynamically to yield the desired ortho-diimide compounds instead of the symmetric dicarboxyphthalimide. Importantly, it is possible to avoid perturbing the aryl halide positions under these reaction conditions, which sets the stage for exploring a broad range of chemistries available for producing imide-decorated aromatic compounds with tailored form and function.

\section{ASSOCIATED CONTENT}

\section{Supporting Information}

\section{AUTHOR INFORMATION}

\section{Corresponding Author \\ *dcao@macalester.edu}

\section{Present Addresses}

$\dagger$ If an author's address is different than the one given in the affiliation line, this information may be included here.

\section{Author Contributions}

The manuscript was written through contributions of all authors. / All authors have given approval to the final version of the manuscript.

\section{ACKNOWLEDGMENT}

This work was supported by the National Science Foundation under Grant No. (NSF 1954975) and the Donors of the American Chemical Society Petroleum Research Fund (57163-UNI1). Computational resources were provided by an NSF-MRI award \#CHE1039925 through the Midwest Undergraduate Computational Chemistry Consortium (MU3C). X-ray crystallographic resources were provided by an NSF-MRI award \#1125975, "MRI Consortium: Acquisition of a Single Crystal X-ray Diffractometer for a Regional PUI Molecular Structure Facility.

\section{REFERENCES}

(1) Ji, C., Cheng, W., Yuan, Q., Müllen, K., Yin, M., From Dyestuff Chemistry to Cancer Theranostics: The Rise of 
Rylenecarboximides. Acc. Chem. Res., 2019 DOI: http://dx.doi.org/10.1021/acs.accounts.9b00221.

(2) Bhosale, S. V., Bhosale, S. V., Bhargava, S. K., Recent Progress of Core-Substituted Naphthalenediimides: Highlights from 2010. Org. Biomol. Chem., 2012, 10, 6455-6468 DOI: http://dx.doi.org/10.1039/C2OB25798J.

(3) Gsänger, M., Bialas, D., Huang, L., Stolte, M., Würthner, F., Organic Semiconductors Based on Dyes and Color Pigments. Adv. Mater., $28, \quad 2016, \quad 3615-3645 \quad$ DOI: http://dx.doi.org/10.1002/adma.201505440.

(4) Wright, W. W., Hallden-Abberton, M., Polyimides. In Ullmann's Encyclopedia of Industrial Chemistry; Wiley-VCH Verlag GmbH \& Co. KGaA, 2000.

(5) Zhan, X., Facchetti, A., Barlow, S., Marks, T. J., Ratner, M. A., Wasielewski, M. R., Marder, S. R., Rylene and Related Diimides for Organic Electronics. Adv. Mater., 2011, 23, 268-284 DOI: http://dx.doi.org/10.1002/adma.201001402.

(6) Chen, X.-K., Zou, L.-Y., Guo, J.-F., Ren, A.-M., An Efficient Strategy for Designing N-Type Organic Semiconductor Materials - Introducing a Six-Membered Imide Ring into Aromatic Diimides. J. Mater. Chem., 2012, 22, 6471-6484 DOI: http://dx.doi.org/10.1039/C2JM15935J.

(7) Bhosale, S. V., Jani, C. H., Langford, S. J., Chemistry of Naphthalene Diimides. Chem. Soc. Rev., 2008, 37, 331-342 DOI: http://dx.doi.org/10.1039/B615857A.

(8) Kobaisi, M. A., Bhosale, S. V., Latham, K., Raynor, A. M., Bhosale, S. V., Functional Naphthalene Diimides: Synthesis, Properties, and Applications. Chem. Rev., 2016, 116, 11685-11796 DOI: http://dx.doi.org/10.1021/acs.chemrev.6b00160.

(9) Würthner, F., Saha-Möller, C. R., Fimmel, B., Ogi, S., Leowanawat, P., Schmidt, D., Perylene Bisimide Dye Assemblies as Archetype Functional Supramolecular Materials. Chem. Rev., 2016, 116, 962-1052 DOI: http://dx.doi.org/10.1021/acs.chemrev.5b00188.

(10) Kumar, S., Shukla, J., Kumar, Y., Mukhopadhyay, P., Electron-Poor Arylenediimides. Org. Chem. Front., 2018, 5, 2254-2276 DOI: http://dx.doi.org/10.1039/C8QO00256H.

(11) Balakrishnan, K., Datar, A., Naddo, T., Huang, J., Oitker, R., Yen, M., Zhao, J., Zang, L., Effect of Side-Chain Substituents on Self-Assembly of Perylene Diimide Molecules: Morphology Control. J. Am. Chem. Soc., 2006, 128, 7390-7398 DOI: http://dx.doi.org/10.1021/ja061810z.

(12) Mei, J., Bao, Z., Side Chain Engineering in Solution-Processable Conjugated Polymers. Chem. Mater., 2014, 26, 604-615 DOI: http://dx.doi.org/10.1021/cm4020805.

(13) Ma, Z., Geng, H., Wang, D., Shuai, Z., Influence of Alkyl Side-Chain Length on the Carrier Mobility in Organic Semiconductors: Herringbone vs. Pi-Pi Stacking. J. Mater. Chem. C, 2016, 4, 45464555 DOI: http://dx.doi.org/10.1039/C6TC00755D.

(14) Sanyal, S., Manna, A. K., Pati, S. K., Effect of Imide Functionalization on the Electronic, Optical, and Charge Transport
Properties of Coronene: A Theoretical Study. J. Phys. Chem. C, 2013, 117, 825-836 DOI: http://dx.doi.org/10.1021/jp310362c.

(15) Yue, W., Gao, J., Li, Y., Jiang, W., Di Motta, S., Negri, F., Wang, Z., One-Pot Synthesis of Stable NIR Tetracene Diimides via Double Cross-Coupling. J. Am. Chem. Soc., 2011, 133, 18054-18057 DOI: http://dx.doi.org/10.1021/ja207630a.

(16) Smith, L. I., Byrkit, G. D., The Constitution of Pyromellitic, Mellophanic and Prehnitic Acids. J. Am. Chem. Soc., 1933, 55, 43054308 DOI: http://dx.doi.org/10.1021/ja01337a075.

(17) Takahashi, M., A New Route to Mellophanic Dianhydride. Bull. Chem. Soc. Jpn., 1968, 41, 265-265 DOI: http://dx.doi.org/10.1246/bcsj.41.265.

(18) Fang, X., Yang, Z., Zhang, S., Gao, L., Ding, M., Polyimides Derived from Mellophanic Dianhydride. Macromolecules, 2002, 35, 8708-8717 DOI: http://dx.doi.org/10.1021/ma0204610.

(19) Li, H., Wang, W., Chen, G., Chen, X., Li, Y., Zhou, H., Fang, X., Highly Soluble Phenylethynyl-Terminated Imides Derived from Mellophanic Dianhydride (MPDA). Polym. Adv. Technol., 2018, 29, 2797-2805 DOI: http://dx.doi.org/10.1002/pat.4402.

(20) Luo, S. M., Stellmach, K. A., Ikuzwe, S. M., Cao, D. D., Redox-Active Heteroacene Chromophores Derived from a Nonlinear Aromatic Diimide. J. Org. Chem., 2019, 84, 10362-10370 DOI: http://dx.doi.org/10.1021/acs.joc.9b01502.

(21) Elter, M., Ahrens, L., Luo, S., Rominger, F., Freudenberg, J., Cao, D., Bunz, U. H., Cata-Annulated Azaacene Bisimides. Chem. - Eur. J., n/a DOI: http://dx.doi.org/10.1002/chem.202101573.

(22) Schmidt, R., Griesbaum, K., Behr, A., Biedenkapp, D., Voges, H.-W., Garbe, D., Paetz, C., Collin, G., Mayer, D., Höke, H., Hydrocarbons. In Ullmann's Encyclopedia of Industrial Chemistry; Wiley-VCH Verlag GmbH \& Co. KGaA, Ed.; Wiley-VCH Verlag GmbH \& Co. KGaA: Weinheim, Germany, 2014; pp. 1-74.

(23) Rose, K. G., Jaber, D. A., Gondo, C. A., Hamilton, D. G., An Expedient Synthesis of Mellitic Triimides. J. Org. Chem., 2008, 73, 3950-3953 DOI: http://dx.doi.org/10.1021/jo800185v.

(24) Vorogushin, A. V., Huang, X., Buchwald, S. L., Use of Tunable Ligands Allows for Intermolecular Pd-Catalyzed C-O Bond Formation. J. Am. Chem. Soc., 2005, 127, 8146-8149 DOI: http://dx.doi.org/10.1021/ja050471r.

(25) Hellberg, J., Dahlstedt, E., Pelcman, M. E., Synthesis of Annulated Dioxins as Electron-Rich Donors for Cation Radical Salts. Tetrahedron, $\quad \mathbf{2 0 0 4}, \quad 60, \quad 8899-8912 \quad$ DOI: http://dx.doi.org/10.1016/j.tet.2004.07.017.

(26) Stupp, S. I., LeBonheur, V., Walker, K., Li, L. S., Huggins, K. E., Keser, M., Amstutz, A., Supramolecular Materials: Self-Organized Nanostructures. Science, 1997, 276, 384-389 DOI: http://dx.doi.org/10.1126/science.276.5311.384.

(27) Cui, H., Webber, M. J., Stupp, S. I., Self-Assembly of Peptide Amphiphiles: From Molecules to Nanostructures to Biomaterials. Pept. Sci., 2010, 94, 1-18 DOI: http://dx.doi.org/10.1002/bip.21328. 